\title{
Hypnotizability, Personality Traits, and The Propensity to Experience Alterations of Consciousness
}

\author{
Etzel Cardeña ${ }^{1} \&$ Devin B. Terhune ${ }^{2}$
}

\footnotetext{
${ }^{1}$ Center for Research on Consciousness and Anomalous Psychology (CERCAP), Department of Psychology, Lund University, Sweden

${ }^{2}$ Department of Experimental Psychology, University of Oxford, UK
}

Corresponding address:

Etzel Cardeña, Ph. D.

Thorsen Professor, Department of Psychology

Center for Research on Consciousness and Anomalous Psychology (CERCAP)

Lund University

Paradisgatan 5P

Lund, 22350

Sweden

Telephone number: (0)46 462228770

Fax (department of psychology) 46462224209

Email: Etzel.Cardena@psy.lu.se 


\begin{abstract}
How hypnotizability relates to personality traits other than absorption has received scant attention even though hypnotizability exhibits clear and stable individual differences. Two personality constructs particularly germane to hypnotizability are mental boundaries and self-transcendence, since they seem to index the propensity to experience alterations in consciousness. We conducted two studies to evaluate their relations with behavioral and experiential measures of hypnotizability, and absorption. In study 1 ( $N=112$ US participants), experiential, but not behavioral, measures of hypnotizability, correlated with the personal (e.g., porosity in interpersonal relations or in states of consciousness), but not the world (e.g., opinions of others), subscale of boundary thinness and with absorption. In Study $2(N=84$ Swedish participants), self-transcendence as a whole, as well as two of its three subscales (self-forgetfulness and transpersonal identification) related to hypnotizability, especially as measured experientially. Absorption correlated with an index of experiential hypnotizability in both studies, but was not reliably related to behavioral hypnotizability. The results suggest that experiential hypnotizability is related to the propensity to experience alterations in consciousness characterized by boundarylessness, self-transcendence, and absorption. They also highlight the importance of supplementing behavioral indices of hypnotizability with experiential measures.

Keywords: hypnotizability, absorption, self-transcendence, mental boundaries, personality traits
\end{abstract}


Individual differences in the propensity to experience spontaneous alterations of consciousness have been described for centuries. Recognition of such differences in the West can be traced back to Plato's classification of the manias (Pieper, 1964) and to the Classical Greek mysteries (Ustinova, 2011). With the development of psychology as a discipline, researchers at the turn of the $19^{\text {th }}$ century studied various alterations of consciousness, foremost hypnosis and dissociation, which denotes a failure of integration of psychological processes (Spiegel \& Cardeña, 1991). William James proposed that individuals vary in their ability to access consciousness "beyond the margins" (Taylor, 1996), as did Théodore Flournoy who wrote "All the difference between mediums and ordinary people, is that with the latter there is practically a very marked trench between dream and waking... With the mediums on the contrary" (Flournoy, 1902, in Shamdasani, 1994). F. W. H. Myers (1903) highlighted the permeability of the boundaries between subliminal (non-conscious) and supraliminal (conscious) processes, maintaining that individual differences in this permeability contributed to creativity, the propensity to experience spontaneous alterations in consciousness, and, sometimes, to psychopathology (Kelly, Kelly, Crabtree, Gauld, Grosso, \& Greyson, 2007). Other important theorists including Kurt Lewin, Paul Federn, and Carl Gustav Jung also posited stronger or weaker forms of porosity among psychological processes and states (Hartmann, 1991). More recently, personality constructs related to the propensity to experience spontaneous alterations in consciousness have been developed, but few attempts have been made to relate them to hypnotizability. This paper aims to investigate the relations between these disparate, but germane, constructs

\section{Hypnotizability and Personality Traits}

Hypnotizability denotes behavioral and experiential responsiveness to suggestions following a hypnotic induction (a set of instructions and suggestions to focus on the hypnotist's communications while minimizing extraneous concerns). Hypnotizability shows substantial 
heritability (Lichtenberg, Bachner-Melman, Gritsenko, \& Ebstein, 2000; Morgan, 1973), which interacts with environmental factors (J. Hilgard, 1979) and is generally stable across the lifespan (Piccione, Hilgard, \& Zimbardo, 1989; but see Fassler, Lynn, \& Knox, 2008). It is associated with a propensity to report spontaneous alterations in consciousness and a variety of anomalous experiences, both during hypnosis (Cardeña, 2005; Cardeña, Jönsson, Terhune, \& MarcussonClavertz, 2013; Pekala \& Kumar, 2007) and in other contexts (Cardeña, Krippner, \& Lynn, 2014; Kumar \& Pekala, 2001), but has only rarely been discussed in the context of a potential personality trait related to such a propensity.

Five-Factor Model (FFM). The search for personality correlates of hypnotizability has been mostly fruitless, with the exception of conceptually similar characteristics such as absorption (Roche \& McConkey, 1990), fantasy proneness (Lynn \& Rhue, 1988), and some aspects of imagery (Rader, Kunzendorf, \& Carrabino, 1996; but see Terhune, Cardeña, \& Lindgren, 2011). Hypnotizability does not show a clear relation to the dimensions of the fivefactor model (FFM) of personality: it correlates weakly with agreeableness, extraversion, and openness to experience (Malinosky \& Lynn, 1999; Nordenstrom, Council, \& Meier, 2002), although only with the imaginative and aesthetic facets of the latter and not with those relating to intellectance (intellect/culture) and liberalism (Glisky \& Kihlstrom, 1993; Glisky, Tatary, Tobias, Kihlstrom, \& McConkey1991; Milling, Miller, Newsome, \& Necrason, 2013).

Self-Transcendence. An alternative personality model to the FFM is the Psychobiological Model of Temperament and Character (PMTC), which describes four inborn temperaments (novelty seeking, harm avoidance, reward dependence, and persistence) and three later-developed characteristics (self-directedness, cooperativeness, and self-transcendence) (Cloninger, Skravic, \& Przybeck, 1993). Most relevant to this paper is self-transcendence (ST), typically measured by the Temperament Character Inventory (TCI), which indexes a sense of 
connectedness with a unified whole (Cloninger et al., 1993; Garcia-Romeu, 2010). A genetic analysis of ST found that it exhibited $90 \%$ unique variance when analyzed along other major character/temperament constructs (Gillespie, Cloninger, Heath, \& Martin, 2003). When measured by the TCI or another questionnaire, ST correlated moderately only with the FFM's openness to experience (De Fruyt, Van de Wiele, \& Van Heeringen, 2000; Levenson, Jennings, Aldwin, \& Shiraishi, 2005; Majeski, 1999, but see Piedmont, 1999) and with the Impulsive Sensation factor of the Zuckerman-Kuhlman Personality Questionnaire (Zuckerman \& Cloninger, 1996). ST correlated strongly or very strongly with various aspects of spirituality but did not correlate with existential well-being (MacDonald \& Holland, 2002).

Two studies have researched the relationship between the PMTC and hypnotizability. The first found only a positive correlation between the characteristic of persistence and hypnotizability, but the study did not include a measure of ST (Lichtenberg, Bachner-Melman, Ebstein, \& Crawford, 2004). Other studies that did include the latter observed a weak correlation between ST and hypnotizability and a strong correlation between ST and absorption (Laidlaw, Dwivedi, Naito, \& Gruzelier, 2005; Ott, 2007).

Absorption. Absorption has been defined as a personality trait underlying the propensity to have episodes of strong attentional involvement and adopting an experiential rather than an instrumental, cognitive set (Tellegen, 1981, 1992; Tellegen \& Atkinson, 1974). A twin study showed that genetic factors accounted for about $50 \%$ of its variance, with most of the other variance attributable to non-shared factors (Tellegen, Lykken, Bouchard, Wilcox, Segal, \& Rich, 1988). Absorption has been shown to correlate with hypnotizability, imagery, fantasy-proneness, daydreaming, alterations of consciousness, dream recall (Roche \& McConkey, 1990; Watson, 2003), an experiential cognitive style (Brown \& Oakley, 1998) and creativity (Manmiller, Kumar, \& Pekala, 2005, who also reported a significant but smaller correlation with 
hypnotizability). The correlation between absorption and hypnotizability has been questioned because the influence of a hypnosis session and other variables such as consistency motivation might increase the correlations between hypnotizability and other personality constructs when administered in the same context (Council, 1993). However, the nature of this effect and the conclusion that a strong context provides an inflated estimate of the relation remains in dispute (Barnier \& McConkey, 1999).

Absorption has also been shown to moderate individual differences in the effect of a hypnotic induction on spontaneous alterations in consciousness. Kumar and Pekala (1988) reported that a hypnotic induction augmented initial phenomenological differences across groups, especially for those high in absorption and hypnotizability, showing a trait (absorption and hypnotizability) by procedure (hypnotic induction) interaction (see also Cardeña, 2011; Cardeña et al., 2013).

Mental Boundaries. The construct of mental boundaries refers to the degree of connectedness or permeability among psychological processes, and between the self and the environment, with people with thin boundaries having a higher degree of connectedness, in contrast with people with thicker boundaries (Hartmann, 1991; Hartmann \& Kunzendorf, 2007). This construct emerged from the observation that chronic nightmare sufferers tend to have both positive cognitive abilities such as creativity as well as distressing experiences, and is consistent with the proposal that the permeability between states of consciousness can be both adaptive or maladaptive (Myers, 1903). Boundary thinness correlates moderately with nightmare frequency, dream recall, and dream image intensity and emotionality (Hartmann \& Kunzendorf, 2007), ostensible psi experiences (Richards, 1996), transliminality (the tendency for psychological contents to "cross into or out of consciousness"), (Houran, Thalbourne, \& Hartmann, 2003; 
Sherwood \& Milner, 2004-2005), openness to experience and neuroticism (Hartmann \& Kunzendorf, 2007), and reports of trauma and negative life events (Rabeyron \& Watt, 2010). Hypnotizability relates to some psychological processes that are consistent with the construct of thin interpersonal boundaries (Hartmann, 1991), such as dream characteristics (Zamore \& Barrett, 1989), creativity (P. Bowers, 1979), and emotional contagion (Cardeña et al., 2009). Indeed, Barrett (1989) found that boundary thinness was positively correlated with hypnotizability $(r=.19)$, spontaneous changes in consciousness during hypnosis $(r=.29)$, and absorption $(r=.54)$. Similar weak correlations between boundary thinness and hypnotizability were reported in two other studies $(r=.16$, in Kunzendorf and Maurer, 1988-89; $r=.20$, in Rader et al., 1996, who also reported a strong correlation between boundary thinness and absorption). However, these studies were limited in at least two respects. None distinguished between the two mental boundary subscales: one (personal) is clearly related to experiences of the self and conscious states (e.g., "When I awake in the morning, I am not sure whether I am really awake for a few minutes," "When I get involved with someone, we sometimes get too close"), whereas the other (world) evaluates concepts and opinions (e.g., "People of different nations are basically very much alike," "A good teacher needs to help a child remain special") that do not seem to have any obvious link to hypnotizability. A further limitation of all three studies is that the scales were administered in the same context, allowing for the possibility that the correlations might have been inflated (Council, 1993).

Another limitation of the majority of the studies assessing the relation between hypnotizability and personality constructs is that most have only measured behavioral but not experiential responsiveness to hypnotic suggestions. Behavioral hypnotizability measures outward responsiveness to hypnotic suggestions, which may involve a "compliance factor" or acquiescence, particularly for the easier suggestions, but not necessarily the experience of 


\section{Hypnotizability and Personality Traits}

becoming absorbed in the suggestions and experiencing them as happening involuntarily (Balthazard \&Woody, 1992, but see Kirsch, Silva, Comey, \& Reed, 1995). In contrast, experiential measures of hypnotizability more directly tap the extent to which an individual had the corresponding suggested experience in an involuntary and/or subjectively compelling manner, or had other spontaneous alterations of consciousness. Experiential and behavioral measures correlate strongly, but are not equivalent (Field, 1965; Kirsch, Council, \& Wickless, 1990; Kirsch, Milling, \& Burgess, 1998). Some, such as the Inventory Scale of Hypnotic Depth (ISHD; Field, 1965), query on general spontaneous changes in consciousness during hypnosis, whereas others such as the Subjective Experiences Scale (SES; Bowers et al., 1990, see below) evaluate changes in consciousness in response to specific suggestions. Furthermore, behavioral and experiential measures of hypnotizability are not interchangeable. For instance, experiential measures were found to better predict individual differences in emotional contagion than behavioral ones (Cardeña et al., 2009). In this paper we describe two studies that evaluated the relation between behavioral and experiential measures of hypnotizability and germane personality constructs.

\section{Study 1}

Study 1 evaluated the relationships among behavioral and experiential measures of hypnotizability, absorption, and psychological boundaries. We predicted that: hypnotizability and absorption would inter-correlate and would be associated more strongly with the mental boundary scale pertaining to subjective experience (personal) than to that related to opinions (world). We further expected that absorption and mental boundary thinnness would correlate more strongly with experiential than with behavioral measures of hypnotizability. 


\section{Method}

Participants. One hundred and twelve North American undergraduates $\left(M_{\text {Age }}=21.41, S D\right.$ $=5.66$; range: $17-53 ; 62.5 \%$ female) volunteered in this study, which was approved by the local IRB.

Materials. Participants were administered or completed the following measures:

The Harvard Group Scale of Hypnotic Susceptibility (HGSHS, Shor \& Orne, 1962) is the most widely used measure of hypnotizability in a group setting, and has good psychometric properties (Woody \& Barnier, 2008). It consists of an induction and 12 behavioral suggestions including ideomotor, auditory hallucination, and posthypnotic amnesia items that are scored dichotomously, resulting in a scoring range of 0 to 12 . Scoring of the posthypnotic amnesia item followed the Kihlstrom and Register criteria (1984).

The Subjective Experiences Scale (SES) for the HGSHS (Kirsch et al., 1990) is a 12-item questionnaire on a five-point response format that measures experiential involvmement during each HGSHS suggestion. Higher scores reflect greater involuntariness and experiential involvement during hypnotic responding. Initial analyses of the scale (Kirsch et al., 1990) showed it to have strong internal reliability and validity, but it is worth pointing out that the correlation between the HGSHS and the SES was .41, which demonstrates that the measures are not equivalent.

The Inventory Scale of Hypnotic Depth (ISHD) includes 38 dichotomously-scored items evaluating spontaneous subjective experiences during a hypnotic procedure, including: a) absorption and internal and external unawareness, b) feelings of automaticity and compulsion, and c) discontinuity from normal experience, with good reported psychometric properties (Field, 1965; see also Terhune \& Cardeña, 2010). 


\section{Hypnotizability and Personality Traits}

The Tellegen Absorption Scale (TAS) is a 34-item, dichotomously-scored scale of the Multidimensional Personality Questionnaire that measures focused attentional deployment, with very good validity and reliability (Tellegen \& Atkinson, 1974, 1992), and which has been used extensively (Roche \& McConkey, 1990).

The Boundary Questionnaire (BQ; Hartmann, 1991) is a 145-item instrument that evaluates mental boundaries and includes an overall score (Sum), and two subscales: personal and world. The higher the scores, the thinner or more permeable are the experienced boundaries of the individual. Analyses excluding the 7 less reliable items (all in the personal subscale) found very high overall reliability. All scale items loaded initially on a single factor and the scale demonstrated good face validity in predicting which groups would score as having thin (e.g., artists) or thick (e.g., naval officers) boundaries (Hartmann, Harrison, \& Zborowski, 2001). Shorter versions of the questionnaire have been developed in the last few years (see Harrison \& Singer, 2013-2014). In this study, the sum scale $(\alpha=.89)$ and personal subscale $(\alpha=.87)$ displayed strong internal consistency, whereas the world subscale $(\alpha=.59)$ exhibited modest internal consistency.

Procedure. Participants were administered all but one of the measures during a single session as part of a hypnosis demonstration outside of any course. In a separate session some months later, a subset of participants completed the TAS as part of an undergraduate course. No link was made between the two contexts insofar as no reference was made to the previous hypnotizability test and students were asked to volunteer to complete the TAS as part of a general psychometric evaluation of the measure, but the experimenter in the first and second sessions was the same person.

Statistical Analyses. Pearson correlation coefficients were computed between measures and the corresponding $p$-values were corrected for multiple comparisons using a false discovery 
rate correction (Benjamini \& Yekutieli, 2001). We also computed the $95 \%$ confidence intervals (CIs) using Bootstrap resampling (10,000 samples, bias-corrected and accelerated percentile method; Efron, 1987). We compared the magnitude of correlations by Bootstrap resampling their difference (10,000 samples) and we report the median difference and 95\% CIs of the distribution of coefficient differences. We interpret $95 \%$ CIs that did not overlap with 0 as indicating a significant difference between two correlations. Finally, stepwise regression analyses were supplemented with Bootstrapping by resampling and re-performing each analysis $(10,000$ samples). In all cases we report the original analysis results and information regarding the percentage of samples in which individual predictors were retained. Because of the smaller sample for the TAS, it was not included in the multiple regression analyses. All analyses were two-tailed.

\section{Results}

The scores for the sample fell within expectable ranges for these research measures (see Table 1 for descriptive statistics). Neither age, all $r \mathrm{~s}<.18$, all $p \mathrm{~s}>.05$, nor sex, all $F \mathrm{~s}<2.10$, all $p \mathrm{~s}>.05$, was associated with any of the research measures.

Table 1 presents the correlation matrix for the research measures. As expected, the HGSHS correlated strongly with the experiential measures of hypnotic responding, which also correlated amongst themselves, but it did not correlate significantly with the boundaries scales or absorption. In contrast, the BQ personal, but not the world, subscale correlated with both experiential measures of hypnotizability (SES and ISHD), and the SES also correlated with the BQ Sum scale. The SES also correlated with a subset of BQ personal subscales (sleep, feelings, interpersonal, and edges, all ps <.05), and the ISHD with an overlapping subset (sleep, feelings, and interpersonal, all $p \mathrm{~s}<.05)$. Absorption correlated $(p \mathrm{~s}<.05)$ strongly with the BQ sum and 
personal, and moderately with BQ world, and with 9 of the 12 BQ subscales (all but neat, edges, and opinions on organizations).

-- Insert Table 1 about here --

We next examined the differences between the correlation magnitudes using Bootstrap resampling in order to more directly test the prediction that hypnotizability and absorption would relate more strongly to boundaries pertaining to subjective experience (BQ personal) than those concerning opinions (BQ world). In clear support of this prediction, the correlation between HGSHS and BQ personal was greater than that between HGSHS and BQ world (median difference: .24, CIs: .04, .41). This was also the case for TAS (median difference: .26, CIs: .05, .51 ), SES (median difference: .32, CIs: .17, .47) and ISHD (median difference: .27, CIs: .09, .45).

Using the same method, we contrasted the magnitudes of the correlations between hypnotizability measures and the BQ personal subscale and TAS in order to examine our second prediction that the personality measures would relate more strongly to experiential than behavioral measures of hypnotizability. The correlation between BQ personal and ISHD did not differ from that between BQ personal and HGSHS (median difference: .06, CIs: -.09, .20), or BQ personal and SES (median difference: .08, CIs: -.04, .19). However, BQ personal's correlation with SES was marginally greater than that with HGSHS (median difference: .13, CIs: .01, .25). The correlation between absorption and the measures of hypnotizability did not differ (HGSHS vs. ISHD: median difference: .13, CIs: -.10, .44; HGSHS vs. SES: median difference: .14, CIs: $.04, .41$; SES vs. ISHD: median difference: .01, CIs: -..14, .18).

To further clarify the relations between boundary thinness and behavioral and experiential measures of hypnotizability, we regressed the BQ personal and world subscales on the hypnotizability measures (the BQ Sum scale was omitted from the analyses because of concerns regarding multicollinearity due its strong correlations with the personal and world subscales). 
When the HGSHS was the outcome variable, no predictors were retained. In contrast, in the prediction of SES scores the model was significant, $R^{2}=.11, F(2,109), 8.18, p<.001$, retaining both BQ personal, $\beta=.41, S E=.10$, and BQ world, $\beta=-.20, S E=.10$. The Bootstrap resampling analysis corroborated these results: BQ personal was retained in $94 \%$ of the samples (median $\beta$ $=.39$, CIs: $.21, .58$ ), whereas BQ world was retained in only $49 \%$ of the samples (median $\beta=-.26$, CIs: $-.41,-.20)$.

The analysis of ISHD scores corroborated that of the SES. The model was significant, $R^{2}=.05, F(1,110)=6.64, p=.011$, retaining only BQ personal, $\beta=.24, S E=.09$. Bootstrap resampling confirmed these results: BQ personal was retained in $75 \%$ of the samples (median $\beta$ $=.34$, CIs: $.20, .53$ ), whereas BQ world was retained in only $36 \%$ of the samples (median $\beta=-.27$, CIs: $-.45,-.20)$.

A final analysis on BQ personal assessed which of the hypnotizability measures was a better predictor of BQ personal scores. The model was significant, $R^{2}=.09, F(1,110)=12.10$, $p<.001$, retaining only SES scores, $\beta=.31, S E=.09, p<.001$. The resampling analysis retained SES in $84 \%$ of the samples (median $\beta=.38$, CIs: $.21, .85$ ), HGSHS in $29 \%$ of the samples (median $\beta$ $=-.38$, CIs: $-.60,-.22$ ), and ISHD in $12 \%$ of the samples (median $\beta=.27$, CIs: $-.43, .45$ ). Overall the various results offer some support for our prediction that the BQ personal subscale would correlate more closely with experiential than with behavioral measures of hypnotizability.

\section{Discussion}

This study examined the relations between behavioral and experiential measures of hypnotizability and the personality constructs of boundary thinness and absorption. Experiential measures of hypnotizability reliably correlated with boundary thinness pertaining to personal states and absorption, whereas the behavioral measure of hypnotizability was unrelated to boundary thinness or absorption. 


\section{Hypnotizability and Personality Traits}

The experiential measures of hypnotizability correlated more strongly with personal than with world mental boundaries. In particular, whereas BQ personal correlated with both experiential measures of hypnotizability and with absorption, BQ world did not correlate significantly with any measure of hypnotizability. Further analyses revealed that BQ personal correlated more strongly with all the hypnotizability measures and absorption than BQ world did. The BQ Sum only correlated weakly with one measure of hypnotizability, but it is likely that this effect was driven by the BQ personal items.

These results are consistent with our hypothesis that hypnotizability would be more closely associated with thinness of psychological boundaries pertaining to personal experience than with boundaries pertaining to opinions and beliefs. The lower internal reliability of the BQ world subscale also suggests that its items do not cohere as well as those of BQ personal, and our analyses on the BQ subscales suggest that the relation between mental boundaries and experiential hypnotizability is mostly driven by intrapersonal and interpersonal permeability and alterations in consciousness (e.g., unusual experiences and involuntariness).

The support for our second prediction, that personality measures would relate more strongly to experiential than behavioral measures of hypnotizability, was more equivocal. Boundary thinness and absorption reliably correlated with experiential measures (SES and ISHD), but not the behavioral measure (HGSHS), of hypnotizability. In particular, experiential responsiveness to hypnotic suggestions (SES) predicted BQ personal scores. However, in only one case did experiential measures correlate more strongly with BQ personal than the behavioural measure (the BQ personal subscale correlated more strongly with the SES than the HGSHS). This is consistent with our previous finding that emotional contagion more strongly relates to experiential than behavioral hypnotizability (Cardeña et al., 2009), and suggests that personality characteristics underlying a propensity to experience alterations in consciousness may be more 
closely related to experiential than behavioral hypnotizability. However, the magnitude and characteristics of this dissociation warrant further research.

The observed pattern of results is consistent with the relation between hypnotizability and emotional contagion (Cardeña et al., 2009) and with the finding that hypnotizability relates to experiential rather than to conceptual aspects of openness to experience (Glisky \& Kihlstrom, 1993; Glisky et al. 1991; Milling et al., 2013). It is of interest that of the three measures of hypnotizability, the one assessing a sense of involuntariness and involvement in the suggestions (SES) was the best predictor of personal boundary thinness, in light of Weitzenhoffer's (1980) statement that a sense of involuntariness is a better measure of hypnotizability than whether the person overtly responds to suggestions.

A notable finding is that behavioral hypnotizability did not correlate with boundary thinness or absorption. Although non-significant, the magnitude of the former relationship ( $r=$ .13) was comparable to that observed in previous studies (Barrett, 1989; Kunzendorf and Maurer, 1988-89; Rader et al., 1996). This suggests a very weak correlation between these constructs, which our other analyses suggest is mostly dependent on the BQ personal subscale. Although the correlation between behavioral hypnotizability and absorption failed to achieve statistical significance, it was not significantly smaller than the significant correlations between absorption and experiential measures of hypnotizability, thereby questioning the possibility of a qualitative difference between the relation between behavioral and experiential measures and absorption. Furthermore, the magnitude of the former correlation was similar to that reported in other studies (Roche \& McConkey, 1990).

\section{Study 2}

In study 2 we evaluated the relationships among behavioral and experiential measures of hypnotizability, absorption, and self-transcendence. We predicted that hypnotizability and 
absorption would inter-correlate and correlate with self-transcendence and that absorption and self-transcendence would correlate more strongly with experiential than with behavioral measures of hypnotizability.

\section{Method}

Participants. Eighty-four $\left(M_{\mathrm{Age}}=23.13, S D=4.62\right.$, range: $18-43 ; 63 \%$ female $)$ Swedish undergraduates participated after ethical approval from the Swedish EPN (IRB) was secured.

Materials. The Modified Tellegen Absorption Scale (MODTAS) is a version of the TAS (Tellegen \& Atkinson, 1974) in which the dichotomous response format was changed to a scale with items anchored at 0 (never) and 4 (very often). The MODTAS has a much better covariance structure than the original TAS and a common factor underlying most of the variance (Jamieson, 2005). The scale exhibited strong internal consistency in this study $(\alpha=.94)$.

The Self-Transcendence Character Scale (ST) is part of the Temperament-Character Inventory. We used the original three subscales: ST1 or self-forgetful vs. self conscious (whether the person experiences a loss of self-other boundaries), ST2 or transpersonal identification vs. self-isolation (whether the person consistently identifies her/himself with a unity transcending the self), and ST3 or spiritual acceptance vs. rational materialism (whether the person holds a worldview including incorporating non-rational, spiritual beliefs) (Cloninger, Przybeck, \& Svrakic, 1993). Although there is controversy on whether the ST is completely characterological (i.e., developmental) in nature and which is the best factorial solution, it has shown overall good psychometric properties (Cloninger, Przybeck, \& Svrakic, 1993; MacDonald \& Holland, 2002). In this study we used the Swedish version (Brändström, Sigvardsson, Nylander, \& Richter, 2008), which exhibited satisfactory internal consistency (ST: $\alpha=.86$; ST1: $\alpha=.84$; ST2: $\alpha=.65$; ST3: $\alpha=.60)$. 
The Waterloo Stanford Group Scale of Hypnotic Susceptibility, Form C (WSGC) is a group-adapted version of the individually-administered Stanford Hypnotic Susceptibility Scale, Form C (Weitzenhoffer \& Hilgard, 1962), and has strong psychometric properties (K. Bowers, 1993, 1998). The WSGC consists of a hypnotic induction followed by 12 suggestions and includes a greater range of cognitive-perceptual suggestions than the HGSHS.

The Experiential Experience Scale for Waterloo-Stanford Group C Scale (EES) measures experiential involvement in WSGC suggestions Participants rate experiential response to each suggestion on a five-point Likert-type scale with scores ranging from 12 to 60. The EES exhibits good validity and reliability, with a mean correlation between experiential and behavioral scores of .62, showing that the measures are not equivalent (Kirsch et al., 1998). It exhibited good internal consistency in this study $(\alpha=.83)$.

The Inventory Scale of Hypnotic Depth (ISHD; $\alpha=.82$; see Study 1).

Procedure. Participants completed the WSGC, EES, and ISHD in a single session. A subset of participants $(n=26)$ could not complete the EES for logistical reasons. Two months later, these participants were administered the ST and MODTAS by a different experimenter and without any reference to the earlier hypnosis session.

Statistical Analyses. The analyses were the same as in Study 1. Because of the smaller sample for the EES, it was not included in the multiple regression analyses.

\section{Results}

Descriptive statistics for the research measures are presented in Table 2. The means for the WSGC and the SES were markedly lower than those for USA samples (Bowers, 1983; Kirsch, Milling, \& Burgess, 1998), but the ST mean was similar to that of a Swedish sample of comparable age (Brändström et al., 2008). None of the research measures correlated with age (all $r \mathrm{~s}<.21$, all $p \mathrm{~s}>.10$ ), but women scored significantly higher than men on the $\mathrm{ST}, F(1,82)=6.81$, 
$p=.011, \eta^{2}=.08$, and ST1 subscale, $F(1,82)=26.21, p<.001, \eta^{2}=.24$, and non-significantly but suggestively higher on the two subjective measures of hypnotizability: EES, $F(1,56)=3.95, p$ $=.052, \eta^{2}=.07$, and ISHD, $F(1,82)=3.60, p=.061, \eta^{2}=.04$. There were no main effects of sex on the WSGC, ST2, ST3, or the MODTAS, $F \mathbf{s}<0.25, p \mathrm{~s}>.8$.

-- Insert Table 2 about here --

Along with inter-correlations between the behavioral and experiential measures of hypnotizability, absorption correlated with the WSGC and ISHD, but not with the EES. The selftranscendence total score correlated with both experiental measures of hypnotizability, but not with the WSGC; ST1 and ST2 correlated with ISHD scores; and ST1 also correlated with EES scores. Finally, absorption correlated strongly with the ST and all of its subscales. All of the ST scales, except ST3, correlated more strongly with the ISHD than with the WSGC, but the Bootstrap analyses found that these differences were not significant (ST: median difference: .11, CIs: -.07, .31; ST1: median difference: .12, CIs: -.08, .34; ST2: median difference: .11, CIs: -.06, .29 ; ST3: median difference: .00, CIs: $-.14, .19)$.

-- Insert Table 3 about here --

To clarify the relations among these variables, a regression analysis evaluated whether the behavioral measure of hypnotizability (WSGC) was best predicted by spontaneous experiences during hypnosis (ISHD), absorption, or the self-transcendence subscales (the ST scale was excluded from the analyses because of concerns regarding multicollinearity). The model was significant, $R^{2}=.38, F(1,82)=51.19, p<.001$, with $\operatorname{ISHD}(\beta=.62, S E=.09)$ being the only independent significant predictor. The resampling analysis retained the ISHD in $100 \%$ of the 
samples (median $\beta=.62$, CIs: $.47, .74$ ) with all other variables being retained in fewer than $11 \%$ of the samples (MODTAS: 10\%; median $\beta=.22$, CIs: -.18, .44; ST1: 8\%; median $\beta=-.19$, CIs: $.33, .30 ;$ ST2: $5 \%$; median $\beta=-.24$, CIs: $-.57, .25$; ST3: $6 \%$; median $\beta=.21$, CIs: $-.21, .40)$.

The analysis on WSGC was repeated using only the personality measures (MODTAS and the ST subscales). The model was significant, $R^{2}=.04, F(1,82)=4.78, p=.032$, with MODTAS $(\beta=.23, S E=.11)$ being the only independent significant predictor. The resampling analysis retained MODTAS in $47 \%$ of the samples (median $\beta=.30$, CIs: $.22, .52$ ) with all other variables being retained in fewer than $21 \%$ of the samples (ST1: $20 \%$; median $\beta=.28$, CIs: .21, .43; ST3: $10 \%$; median $\beta=.27$, CIs: $-.30, .45 ;$ ST2: $8 \%$; median $\beta=.23$, CIs: $-.54, .42$ ).

The personality measures were next used to predict ISHD scores. The model was significant, $R^{2}=.07, F(1,82)=7.63, p=.007$, with MODTAS $(\beta=.29, S E=.11)$ being the only independent significant predictor. The resampling analysis provided somewhat conflicting results with the principal analysis. MODTAS was retained in $46 \%$ of the samples (median $\beta=.34$, CIs: $.22, .54$ ), and the ST1 was also retained in $46 \%$ of the samples (median $\beta=.32$, CIs: $.22, .48$ ). The remaining two variables were retained in fewer than $17 \%$ of the samples (ST2: $16 \%$; median $\beta$ $=.32$, CIs: $-.28, .50$; ST3: 6\%; median $\beta=-.24$, CIs: $-.42, .36)$.

Behavioral and experiential measures of hypnotizability (HGSHS and ISHD) and absorption (MODTAS) were next used to predict ST subscale scores. For ST1 (selfforgetfulness), the model was significant, $R^{2}=.14, F(1,83)=14.78, p<.001$, with $\operatorname{MODTAS}(\beta$ $=.39, S E=.10$ ) being the only independent significant predictor. The resampling analysis was again consistent with the regression analysis: MODTAS was retained in $87 \%$ of the samples (median $\beta=.38$, CIs: $.23, .57)$, ISHD was retained in less than half of the samples $(42 \%$; median $\beta$ $=.28$, CIs: $.20, .53$ ), and WSGC was retained in only $12 \%$ of the samples (median $\beta=.22$, CIs: $.41, .39)$. 
The model for ST2 (transpersonal identification) was significant, $R^{2}=.38, F(1,82)=50.82$, $p<.001$, with MODTAS $(\beta=.62, S E=.09)$ again being the only independent significant predictor. The resampling analysis corroborated this result with MODTAS being retained in $100 \%$ of the samples (median $\beta=.62$, CIs: $.45, .75$ ) and the ISHD and WSGC retained in fewer than $15 \%$ of the samples (ISHD: $13 \%$; median $\beta=.22$, CIs: $.16, .38$; WSGC: $7 \%$; median $\beta=-.20$, CIs: $-.37, .25)$.

Finally, for ST3 (spiritual acceptance), the model was significant, $R^{2}=.13, F(1,82)=12.84$, $p<.001$, with MODTAS $(\beta=.37, S E=.10)$ being the only independent significant predictor. The resampling analysis corroborated this result with MODTAS being retained in $92 \%$ of the samples (median $\beta=.38$, CIs: .23, .57), whereas ISHD and WSGC were both retained in fewer than $10 \%$ of the samples (ISHD: $6 \%$; median $\beta=.21$, CIs: $-.32, .39$; WSGC: $7 \%$; median $\beta=.25$, CIs: $-.26, .41)$.

\section{Discussion}

This study examined the relationship between behavioral and experiential measures of hypnotizability and self-transcendence and absorption with a different set of measures than in Study 1. Measures of self-transcendence reliably correlated with experiential, but not behavioral, measures of hypnotizability, whereas absorption correlated with both types of measures. Absorption was reliably stronger than hypnotizability in predicting different facets of selftranscendence.

As in Study 1, there was a tendency for relations between personality measures and hypnotizability to be restricted to experiential measures of hypnotizability. Self-transcendence, in particular self-forgetfulness, correlated weakly to moderately with both experiential measures of hypnotizability, whereas transpersonal identification correlated with only one of the experiential measures (ISHD). However, correlations with the ISHD were not significantly different from 
those with the WSGC, so as in Study 1, the discrepancy between behavioral and experiential measures was not robust. Notably, the third factor of self-transcendence, spiritual identification, did not correlate with any measure of hypnotizability. This suggests that experiential changes during hypnosis relate to facets of self-transcendence linked to transient changes in experience and a sense of unity rather than to a conceptual shift in worldview (cf. Garcia-Romeu, 2010). Also as in Study 1, behavioral hypnotizability proved to be a weak correlate of personality measures. It correlated weakly with absorption, but within the range of previous studies (Roche \& McConkey, 1990), and did not correlate with self-transcendence. It is plausible that the former relation is driven by experiential responsiveness to hypnosis.

Self-transcendence related more strongly to absorption than to hypnotizability. Absorption had moderate to strong correlation with all ST factors and was the only independent predictor of ST and its subscales. These results suggest that although spontaneous alterations in experience during hypnosis relate to self-transcendence, this relationship may be mediated by absorption. Worth pointing out is that we corroborated the positive correlation between ST and hypnotizability (but only experientially) and absorption that Laidlaw et al. reported (2005), but controlling for a possible context effect.

The lower hypnotizability scores, especially for the WSGC (about one third lower) than those for a North American sample (Bowers, 1993) suggest that non-native speakers may find this measure more difficult to interpret than the HGSHS. The higher scores of women in the ST, ST1 and (suggestively) in experiential hypnotizability is consistent with some previous studies (Cardeña et al., 2007; Kirsch et al., 1998; MacDonald \& Holland, 2002), suggesting that women may be slightly more prone to experience (or report) changes in consciousness in hypnotic and other contexts.

\section{General Discussion}




\section{Hypnotizability and Personality Traits}

These two studies show evidence of a generally coherent set of relationships between hypnotizability, particularly measured experientially, and the constructs of absorption, boundary thinness, and self-transcendence. A consistent finding overall in both studies was that experiential (rather than behavioral) hypnotizability related to traits indexing changes of consciousness outside the hypnotic context: personal mental boundary thinness, self-transcendence, and absorption. Another consistent finding is that experiential hypnotizability relates to personal, experiential aspects of the constructs of mental boundaries and self-transcendence, rather than to its more conceptual dimensions. These results suggest that experiential responsiveness to hypnosis is associated with the tendencies to have thin personal boundaries, self-transcendent experiences, and to become absorbed in one's activities. They further highlight the importance of differentiating between experiential and behavioral measures of hypnotizability and suggest that the general failure to identify personal correlates of hypnotizability may be due in part to the tendency to neglect experiential, in favor of behavioral, hypnotizability (REF).

Across studies, different personality constructs tended to relate more strongly to experiential measures than behavioral measures of hypnotizability. The HGSHS did not correlate with any boundary thinness scales in Study 1, and in Study 2 we similarly found that measures of self-transcendence correlated with experiential, but not behavioral, measures of hypnotizability, although the difference between the correlations did not achieve significance. These results strongly suggest that individual differences in personality traits relate more to experiential than behavioral measures of hypnotizability, although it remains unclear whether this dissociation is qualitative or quantitative in nature. This apparent distinction may be explained by the fact that hypnotizability includes both a "compliance" factor (i.e., to enact the suggested behaviors) as well as an experiential factor related to having the corresponding suggested experiences. The latter involves experiencing the suggestions as if they happened on their own, or as if some 
counterfactual event such as holding an imaginary book were physically real. The distinction between behavioral acquiescence and consciousness change is consistent with Shor's (1962) proposal that hypnosis involves various factors including a social suggestibility component or role-enactment, and "trance," or alterations in consciousness (Shor, 1962). It may be that despite their high correlations with behavioral measures of hypnotizability, experiential measures are more sensitive measures of the classic suggestion effect (cf. Weitzenhoffer, 1980). The regression findings suggest that the propensities for absorption and self-transcendence facilitate unusual experiences during hypnosis. These experiences may shape the experiential concomitants of hypnotic responding, which in turn may influence behavioral hypnotizability. However, it needs to be acknowledged that the HGSHS and WSGC are work-sample tasks (Woody \& Barnier, 2008) and thus it may be necessary to create a related context for measures of boundary thinness and self-transcendence to more accurately capture their relation with behavioral hypnotizability.

The results strongly suggest that within the constructs of mental boundaries and selftranscendence subscales that evaluate subjective experiences (the personal subscale in mental boundaries, and ST 1 and ST 2 in self-transcendence) tap a different domain than those that refer to opinions and general worldviews. Whereas the former were clearly related to experiential hypnotizability and absorption, the latter were not related to hypnotizability and were not as strongly related to absorption. These results help to elucidate the specific components of boundary thinness and self-transcendence related to hypnotizability.

Although some of the significant correlations in both studies were modest, Balthazard and Woody (1992, p. 37) had remarked earlier that considering the factorial complexity "and attenuation due to unreliability, a correlation of about .35 between the total hypnosis score and a given questionnaire measure is about all that can be expected." It bears mentioning that the effect size for the correlations between self-transcendence and various measures of hypnotizability 


\section{Hypnotizability and Personality Traits}

compare favorably with reported correlations between hypnotizability and openness to experience even when analyzing different factors of the traits.

Our results also support previous findings that the relation between hypnotizability and absorption (and other personality traits) is not dependent on being measured in the same testing context. We replicated other studies showing that the relation between different measures and hypnotizability, especially measured experientially, are present and consistent even if measured out of context (cf. Roche \& McConkey, 1990). The results of study 2 showed women to be slightly more likely to experience or report self-transcendence and (indeterminately) experiential changes during hypnosis, results worth investigating further.

A number of limitations of the two studies should be acknowledged. The $n \mathrm{~s}$, especially for some measures, were relatively low. We did not evaluate other personality constructs such as transliminality or positive schizotypy that seem to at least partly tap the same underlying construct as mental boundaries, absorption, and self-transcendence, nor did we measure in the same study self-transcendence and mental boundaries. Furthermore, we did not differentiate between possible sub-groups of high hypnotizables. Crawford (1982) reported three different factors in her study of hypnotizability: one involving high hypnotizability, imagery, absorption, and positive daydreaming, another one involving dysphoric daydreaming, and the third one lacking attentional control. Along similar lines, we have found consistent evidence for two subtypes of high hypnotizables, one that exhibits stronger imagery abilities and tends to experience more imagery and positive emotions spontaneously during hypnosis; the second experiences a strong sense of involuntariness during hypnotic responding, greater emotionality and strong shifts in attentional states following a hypnotic induction, poorer working memory, a traumatic history, and greater pathological fantasy (a similar concept to dysphoric daydreaming) (Marcusson-Clavertz, Terhune, \& Cardeña, 2012; Terhune \& Cardeña, 2010; Terhune, Cardeña, 
\& Lindgren, 2011a,b). There is also evidence that high hypnotizables who are also highly dissociative report less absorption (Barrett, 1996) and greater involuntariness during hypnotic responding (Terhune et al., 2011). Future research would benefit from considering the possible role of dissociative tendencies and general psychopathology on the relations between the personality constructs we evaluated here and experiential and behavioral hypnotizability. Finally, our studies included samples from two different countries, but it was homogeneous in including mostly students from Western industrialized societies, thus we cannot generalize to other groups or cultures. Longitudinal and cross-cultural research will also help clarify how the propensity to have episodes of absorption, self-transcendence, and alterations of consciousness, manifests in different cultures (especially those differing substantially from industrialized ones (Cardeña \& Krippner, 2010) and across the lifespan (Granqvist, Reijman, \& Cardeña, 2011).

In sum, our studies underline the importance of differentiating behavioral and experiential aspects of hypnosis and including measures of involuntariness and other experiential changes when conducting hypnosis research. They also show that although hypnotizability may not be clearly related to traditional personality traits such as those measured by the Big Five, it is associated with traits such as personal mental boundaries, self-transcendence, and absorption, all of which seem to map onto a propensity to have non-conceptual, non-dual modes of experiencing.

\section{Acknowledgements}

This research was supported by the Bial Foundation bursaries 50-04 (E. C.) and 54-06 (D.B.T. and E. C.). D.B.T. is currently supported by a Marie Sklodowska-Curie Intra-European Fellowship within the 7th European Community Framework. 


\section{References}

Balthazard, C. G., \& Woody, E. Z. (1992). The spectral analysis of hypnotic performance with respect to "absorption." International Journal of Clinical and Experimental Hypnosis, 40, 2143.

Barnier, A. J., \& McConkey, K. M. (1999). Absorption, hypnotizability and context: Nonhypnotic contexts are not all the same. Contemporary Hypnosis, 16, 1-8.

Barrett. D. (1989, April). The relationship of thin versus thick boundaries to hypnotic susceptibility. Paper presented to the Eastern Psychological Association, Boston, MA.

Benjamini, Y., \& Yekutieli, D. (2001). The control of the false discovery rate in multiple testing under dependency. Annals of Statistics, 29, 1165-1188.

Bowers, K.S. (1993). The Waterloo-Stanford Group C (WSGC) scale of hypnotic susceptibility: Normative and comparative data. International Journal of Clinical and Experimental Hypnosis, 41, 35-46.

Bowers, K.S. (1998). Waterloo-Stanford Group Scale of Hypnotic Susceptibility, Form C: Manual and response booklet. International Journal of Clinical and Experimental Hypnosis, $46,250-268$.

Bowers, P. (1979). Hypnosis and creativity: The search for the missing link. Journal of Abnormal Psychology, 88, 564-572. 
Brown, R. J., \& Oakley, D. A. (1998). Hypnotic susceptibility and holistic/emotional styles of thinking. Contemporary Hypnosis, 15, 76-83.

Brändström, S., Sigvardsson, S., Nylander, P. O., \& Richter, J. (2008). The Swedish version of the Temperament and Character Inventory $(T C I)$ : A cross-validation of age and gender influences. European Journal of Psychological Assessment, 24, 14-21.

Cardeña, E. (2005). The phenomenology of deep hypnosis: Quiescent and physically active. International Journal of Clinical \& Experimental Hypnosis, 53, 37-59.

Cardeña, E. (2011). Altering consciousness: Setting up the stage. In E. Cardeña, \& M. Winkelman (Eds.), Altering consciousness. Multidisciplinary perspectives. Volume I: History, culture, and the humanities (pp. 1-21). Santa Barbara, CA: Praeger.

Cardeña, E., Kallio, S., Terhune, D., Buratti, S., \& Lööf, A. (2007). The effect of translation and sex on hypnotizability testing. Contemporary Hypnosis, 24, 154-160 (see also erratum: Vol 25(2), Jun 2008, pp. 110.).

Cardeña, E., \& Krippner, S. (2010). The cultural context of hypnosis. In Lynn, S. J., J. W. Rhue, \& Kirsch, I. (Eds.) Handbook of clinical hypnosis $2^{\text {nd }}$ Ed (pp. 743-771). Washington, D. C: American Psychological Association.

Cardeña, E., Krippner, S., \& Lynn, S. J. (2014). Anomalous experiences: An integrative summary. In E. Cardeña, S. J., Lynn, \& S. Krippner (Eds.), Varieties of anomalous experience: Examining the scientific evidence. $2^{\text {nd }}$ ed. (pp. 409-426). Washington, DC: American Psychological Association.

Cardeña, E., Jönsson, P., Terhune, D. B., \& Marcusson-Clavertz, D. (2013). The neurophenomenology of neutral hypnosis. Cortex, 49, 375-385.

Cardeña, E., Terhune, D. B., Lööf, A., \& Buratti, S. (2009). Hypnotic experience is related to emotional contagion. International Journal of Clinical and Experimental Hypnosis, 57, 33-46. 
Cloninger, C.R., Przybeck, T. R., \& Svrakic, D.M. (1993). The tridimensional personality questionnaire: U.S. normative data. Psychological Reports, 69, 1047-1057.

Cloninger, C. R., Svrakic, D. M., \& Przybeck, T. R. (1993). A psychobiological model of temperament and character. Archives of General Psychiatry, 50, 975-990.

Council, J. R. (1993). Context effects in personality research. Current Directions in Psychological Science, 2, 31-34.

Crawford, H. J. (1982). Hypnotizability, daydreaming styles, imagery vividness, and absorption: A multidimensional study. Journal of Personality and Social Psychology, $42,915-926$.

De Fruyt, P., Van de Wiele, L., \& Van Heeringen (2000). Cloninger's psychobiological model of temperament and character and the five-factor model of personality. Personality and Individual Differences, 29, 441-452.

Efron, B. (1987). Better bootstrap confidence intervals. Journal of the American Statistical Association, 82, 171-185.

Fassler, O., Lynn, S. J., \& Knox, J. (2008). Is hypnotic suggestibility a stable trait? Consciousness and Cognition, 240-253.

Field, P. B. (1965). An inventory scale of hypnotic depth. International Journal of Clinical and Experimental Hypnosis, 13, 238-249.

Garcia-Romeu, A. (2010). Self-transcendence as a measurable transpersonal construct. Journal of Transpersonal Psychology, 42, 26-47.

Gillespie, N. A., Cloningerr, C. R., Heath, A. C. \& Marti, N. G. (2003). The genetic and environmental relationship between Cloninger's dimensions of temperament and character. Personality and Individual Differences, 35, 1931-1946.

Glisky, M. L., \& Kihlstrom, J. F. (1993). Hypnotizability and facets of openness. International 
Journal of Clinical and Experimental Hypnosis, 41, 112-123.

Glisky, M. L., Tataryn, D. J., Tobias, B. A., Kihlstrom, J. F., \& McConkey, K. M. (1991). Absorption, openness to experience, and hypnotizability. Journal of Personality and Social Psychology, 60, 263-272.

Granqvist, P., Reijman, S., \& Cardeña E. (2011). Altered consciousness and human development. In E. Cardeña, \& M. Winkelman. Altering consciousness. Multidisciplinary perspectives. Volume II: Biological and psychological perspectives (pp. 211-234). Santa Barbara, CA: Praeger.

Harrison, A., \& Singer, J. (2013-2014). Boundaries in the mind: Historical context and current research using the boundary questionnaire. Imagination, Cognition, and Personality, 33, 205215.

Hartmann, E. (1991). Boundaries of the mind: A new psychology of personality. New York, NY: Basic Books.

Hartmann, E., Harrison, R., \& Zborowski, M. (2001). Boundaries in the mind: Past research and future directions. North American Journal of Psychology, 3, 347-368.

Hartmann, E., \& Kunzendorf, R. G. (2007). Boundaries and dreams. Imagination, Cognition and Personality, 26, 101-115.

Hilgard, J. (1979). Personality and hypnosis: A study of the imaginative involvement. Chicago, Il: Chicago University Press.

Houran, J., Thalbourne, M. A., \& Hartmann, E. (2003). Comparison of two alternative measures of the boundary construct. Perceptual and Motor Skills, 96, 311-323.

Jamieson, G. A. (2005). The modified Tellegen Absorption Scale: A clearer window on the structure and meaning of absorption. Australian Journal of Clinical and Experimental Hypnosis, 33, 119-139. 
Kelly, E. F., Kelly, E. W., Crabtree, A., Gauld, A., Grosso, M. \& Greyson, B. (2007). Irreducible mind: Toward a psychology for the $21^{\text {st }}$ century. Lanham, MD: Rowan \& Littlefield.

Kihlstrom, J. F., \& Register, P.A. (1984). Optimal scoring of amnesia on the Harvard Group Scale of Hypnotic Susceptibility, Form A. International Journal of Clinical and Experimental Hypnosis, 32, 51-57.

Kirsch, I., Council, J. R., \& Wickless, C. (1990). Subjective scoring for the Harvard Group Scale of Hypnotic Susceptibility, Form A. International Journal of Clinical and Experimental Hypnosis, 38, 112-124.

Kirsch, I., Milling, L. S., \& Burgess, C. (1998). Experiential scoring for the Waterloo-Stanford Group C Scale. International Journal of Clinical and Experimental Hypnosis, 46, 269-279.

Kirsch, I., Silva, C. E., Comey, G., \& Reed, S. (1995). A spectral analysis of cognitive and personality variables in hypnosis: Empirical disconfirmation of the two-factor model of hypnotic responding. Journal of Personality and Social Psychology, 69, 167-175.

Kumar, V. K., \& Pekala, R. J. (1988). Hypnotizability, absorption, and individual differences in phenomenological experience. International Journal of Clinical and Experimental Hypnosis, $36,80-88$.

Kumar, V.K., \& Pekala, R.J. (2001). Relation of hypnosis-specific attitudes and behaviors to paranormal beliefs and experiences. In J. Houran, \& R. Lange (Eds.), Hauntings and poltergeists: Multidisciplinary perspectives (pp. 260-279). Jefferson, NC: McFarland.

Kunzendorf, R. G., \& Maurer, J. (1988-89). Hypnotic attenuation of the "boundaries" between emotional, visual, and auditory sensations. Imagination, Cognition and Personality, 8, 225234. 
Laidlaw, T. M., Dwivedi, P., Naito, A., \& Gruzelier, J. H. (2005). Low self-directedness (TCI), mood, schizotypy and hypnotic susceptibility. Personality and Individual Differences, 39, $469-480$.

Levenson, M. R., Jennings, P. A., Aldwin, C. M., \& Shiraishi, R. W. (2005). Self-transcendence: Conceptualization and measurement. International Journal of Aging \& Human Development, $60,127-143$.

Lichtenberg, P., Bachner-Melman, R., Ebstein, R. P., \& Crawford, H. J. (2004). Hypnotic susceptibility: Multidimensional relationships with Cloninger's tridimensional personality questionnaire, COMT polymorphisms, absorption, and attentional characteristics. International Journal of Clinical and Experimental Hypnosis, 52, 47-72.

Lichtenberg, P., Bachner-Melman, R., Gritsenko, I., \& Ebstein, R. P. (2000). Exploratory association between cathechol-O-methyltransferase (COMT) high/low enzyme activity polymorphism and hypnotizability. American Journal of Medical Genetics, 4, 771-774.

Lynn, S. J., \& Rhue, J. W. (1988). Fantasy proneness: Hypnosis, developmental antecedents, and psychopathology. American Psychologist, 43, 35-44.

MacDonald, D. A., \& Holland, D. (2002). Examination of the psychometric properties of the temperament and character inventory self-transcendence dimension. Personality and Individual Differences, 32, 1013-1027.

Majeski, R. A. (1999). The relationship of transpersonal self-transcendence, extraversion, openness to experience, and psychological well-being in mature adult female meditators and non-meditators. Dissertation Abstracts International: Section B: The Sciences and Engineering, 59 (10-B), 5600. 
Malinoski, P., \& Lynn, S.J. (1999). The plasticity of very early memory reports: Social pressure, hypnotizability, compliance, and interrogative suggestibility. International Journal of Clinical and Experimental Hypnosis, 47, 320-345.

Manmiller, J. L., Kumar, V. K., \& Pekala, R. J. (2005). Hypnotizability, creative capacity, creativity styles, absorption, and phenomenological experience during hypnosis. Creativity Research Journal, 17, 9-24.

McClenon, J. (2001). Wondrous healing: Shamanism, human evolution, and the origin of religion. DeKalb, IL: University of Northern Illinois Press.

Milling, L. S., Miller, D. S., Newsome, D. L., \& Necrason, E. S. (2013). Hypnotic responding and the Five Factor Personality Model: Hypnotic analgesia and Openness to Experience. Journal of Research in Personality, 47, 128-131.

Morgan, A. H. (1973). The heritability of hypnotic susceptibility in twins. Journal of Abnormal Psychology, 82, 55-61.

Muchinsky, P. M. (1996). The correction for attenuation. Educational \& Psychological Measurement, 56, 63-75.

Myers, F. W. H. (1903). Human personality and its survival of bodily death (2 vols). London, UK: Longmans, Green.

Nordenstrom, B., Council, J. R., \& Meier, B. P. (2002). Hypnotizability and the "Big Five." International Journal of Clinical and Experimental Hypnosis, 50, 276-281.

Ott, U. (2007). States of absorption: In search of neurobiological foundations. In In G. A. Jamieson (Ed.), Hypnosis and conscious states: The cognitive neuroscience perspective (pp. 257-270). Oxford, UK: Oxford University Press.

Pekala, R. J., \& Kumar, V. K. (2007). An empirical-phenomenological approach to quantifying consciousness and states of consciousness: With particular reference to understanding the 
nature of hypnosis. In G.A. Jamieson (Ed.), Hypnosis and conscious states: The cognitive neuroscience perspective (pp. 167-194). Oxford, UK: Oxford University Press.

Piccione, C., Hilgard, E. R., \& Zimbardo, P. G. (1989). On the degree of stability of measured hypnotizability over a 25 year period. Journal of Personality and Social Psychology, 56, 289295.

Piedmont. R. L. (1999). Does spirituality represent the sixth factor of personality? Spiritual transcendence and the five-factor model. Journal of Personality, 67, 985-1013.

Pieper, J. (1964). Love and inspiration: A study of Plato's Phaedrus. London, UK: Faber and Faber.

Rabeyron, T., \& Watt, C. (2010). Paranormal experiences, mental health and mental boundaries, and psi. Personality and Individual Differences, 48, 487-492.

Rader, C. M., Kunzendorf, R. G., \& Carrabino, C. (1996). The relation of imagery vividness, absorption, reality boundaries and synesthesia to hypnotic states and traits. In R. G.

Kunzendorf, N. P. Spanos, \& B. Wallace (Eds.) (1996). Hypnosis and imagination (pp. 99121). Amityville, NY, US: Baywood.

Richards, D. G. (1996). Boundaries in the mind and subjective interpersonal psi. Journal of Parapsychology, 60, 227-240.

Roche, S. M., \& McConkey, K. M. (1990). Absorption: Nature, assessment, and correlates. Journal of Personality and Social Psychology, 59, 91-101.

Shamdasani, S. (1994). Encountering Hélène: Théodore Flournoy and the genesis of subliminal psychology. In T. Flournoy From India to the Planet Mars: A case of multiple personality with imaginary landscapes (pp. xi-li). Princeton, NJ: Princeton University Press.

Sherwood, S. J., \& Milner, M. E. (2004-2005). The relationship between transliminality and boundary structure subscales. Imagination, Cognition, and Personality, 22, 369-378. 
Shor, R. E. (1962). Three dimensions of hypnotic depth. International Journal of Clinical and Experimental Hypnosis, 10, 23-38.

Shor, R. E., \& Orne, E. C. (1962). Harvard Group Scale of Hypnotic Susceptibility: Form A. Palo Alto, CA: Consulting Psychologists Press.

Spiegel, D., \& Cardeña, E. (1991). Disintegrated experience: The dissociative disorders revisited. Journal of Abnormal Psychology, 100, 366-378.

Tabachnick, B.G., \& Fidell, L.S. (2007). Using multivariate statistics (5 ${ }^{\text {th }}$ Ed.). Boston, MA: Pearson Education, Inc.

Taylor, E. (1996). William James on consciousness beyond the margin. Princeton, NJ: Princeton University Press.

Tellegen, A. (1981). Practicing the two disciplines for relaxation and enlightenment: Comment on Qualls \& Sheehan. Journal of Experimental Psychology: General, 110, 217-226.

Tellegen, A. (1992). Notes on the structure and meaning of the MPQ absorption scale. University of Minnesota. Typescript.

Tellegen, A., \& Atkinson, G. (1974). Openness to absorbing and self-altering experiences (“absorption"), a trait related to hypnotic susceptibility. Journal of Abnormal Psychology, 83, $268-277$.

Tellegen, A., Lykken, D. T., Bouchard, T. J., Wilcox, K. J., Segal, N. L., \& Rich, S. (1988). Personality similarity in twins reared apart and together. Journal of Personality and Social Psychology, 54, 1031-1039.

Terhune, D. B., \& Cardeña, E (2010). Differential patterns of spontaneous experiential response to a hypnotic induction: A latent profile analysis. Consciousness and Cognition, 19, 11401150. 
Terhune, D. B., Cardeña, E., \& Lindgren, M. (2011). Dissociative tendencies and individual differences in high hypnotic suggestibility. Cognitive Neuropsychiatry, 16, 113-135.

Ustinova, Y. (2011). Consciousness alteration practices in the West from Prehistory to Late Antiquity. In E. Cardeña \& M. Winkelman (Eds.), Altering consciousness. Multidisciplinary perspectives. Volume I: History, culture, and the humanities (pp. 45-72). Santa Barbara, CA: Praeger.

Watson, D. (2003). To dream, perchance to remember: Individual differences in dream recall. Personality and Individual Differences, 34, 1271-1286.

Weitzenhoffer, A. M. (1980). Hypnotic susceptibility revisited. American Journal of Clinical Hypnosis, 22, 130-146.

Zamore, N., \& Barret, D. (1989). Hypnotic susceptibility and dream characteristics. Psychiatric Journal of the University of Ottawa, 14, 572-574.

Zuckerman, M., \& Cloninger, R. C. (1996). Relationships between Cloninger's, Zuckerman's and Eysenck's dimensions of personality. Personality and Individual Differences, 21, 283-285. 
Table 1

Descriptive Statistics and Correlation Matrix for Measures in Study $1(N=112)$

\begin{tabular}{lccccccc}
\hline & $M(S D)$ & HGSHS & SES & ISHD & TAS $^{\dagger}$ & BQ Sum & BQ Personal \\
\hline HGSHS & $6.48(2.75)$ & & & & & \\
SES & $36.30(9.80)$ & $.82 * * *$ & & & & & \\
ISHD & $19.18(8.36)$ & $.65 * * *$ & $.79 * * *$ & & & & \\
TAS & $20.51(6.71)$ & .26 & $.41^{* *}$ & $.40 * *$ & & & \\
BQ Sum & $282.64(40.37)$ & .13 & $.25 *$ & .18 & $.56 * * *$ & & \\
BQ Personal & $191.69(31.84)$ & .18 & $.31 * *$ & $.24 *$ & $.58 * * *$ & $.95 * * *$ & \\
BQ World & $282.64(40.37)$ & -.05 & -.01 & -.04 & $.32 *$ & $.72 * * *$ & $.48 * * *$ \\
\hline
\end{tabular}

Notes. HGSHS = Harvard Group Scale of Hypnotic Susceptibility; SES = Subjective Experiences Scale for the HGSHS; ISHD = Inventory Scale of Hypnotic Depth; TAS = Tellegen Absorption Scale. $\mathrm{BQ}=$ Boundary Questionnaire.

${ }^{\dagger} n=61 . * p<.05, * * p<.01, * * * p<.001$ 
Table 2

Descriptive Statistics for Measures in Study 2 for Women $(n=53)$, Men $(n=31)$, and the Total Sample $(N=84)$

\begin{tabular}{|c|c|c|c|}
\hline & Women & Men & Total \\
\hline & $M(S D)$ & $M(S D)$ & $M(S D)$ \\
\hline WSGC & $4.28(1.97)$ & $4.32(2.37)$ & $4.30(2.12)$ \\
\hline EES & $30.64(8.30)$ & $26.40(7.69)$ & $28.81(8.25)$ \\
\hline ISHD & $16.79(8.37)$ & $13.26(8.00)$ & $15.49(8.37)$ \\
\hline MODTAS & $52.70(23.11)$ & $53.93(23.30)$ & $53.15(23.05)$ \\
\hline ST & $13.79(5.94)$ & $10.29(5.92)$ & $12.50(6.14)$ \\
\hline Self-forgetfulness (ST 1) & $6.81(3.00)$ & $3.32(3.04)$ & $5.52(3.44)$ \\
\hline Transpersonal identification (ST 2) & $4.58(2.39)$ & $4.68(2.70)$ & $4.62(2.49)$ \\
\hline Spiritual acceptance (ST 3) & $2.40(1.86)$ & $2.29(1.60)$ & $2.36(1.76)$ \\
\hline
\end{tabular}

Notes. WSGC = Waterloo Stanford Group Scale of Hypnotic Susceptibility, Form C; EES = Experiential Experience Scale for the WSGC; ISHD = Inventory Scale of Hypnotic Depth; MODTAS = Modified Tellegen Absorption Scale; $\mathrm{ST}=$ Self-Transcendence Character Scale. 
Table 3

Correlation Matrix for Measures in Study $2(N=84)$

\begin{tabular}{|c|c|c|c|c|c|c|c|}
\hline & $\mathrm{EES}^{\dagger}$ & ISHD & MODTAS & $\mathrm{ST}$ & ST 1 & ST 2 & ST 3 \\
\hline WSGC & $.82 * * *$ & $.62 * * *$ & $.24 *$ & .18 & .17 & .13 & .13 \\
\hline EES & & $.82 * * *$ & .19 & $.34 *$ & $.36 *$ & .18 & .17 \\
\hline ISHD & & & $.29 *$ & $.29 *$ & $.29 *$ & $.24 *$ & .13 \\
\hline MODTAS & & & & $.58 * * *$ & $.39 * * *$ & $.62 * * *$ & $.37 * *$ \\
\hline ST & & & & & $.85 * * *$ & $.81 * * *$ & $.69 * * *$ \\
\hline ST 1 & & & & & & $.45 * * *$ & $.35 * *$ \\
\hline ST 2 & & & & & & & $.51 * * *$ \\
\hline
\end{tabular}

Notes. WSGC = Waterloo Stanford Group Scale of Hypnotic Susceptibility, Form C; EES = Experiential

Experience Scale for the WSGC; ISHD = Inventory Scale of Hypnotic Depth; MODTAS = Modified Tellegen Absorption Scale; ST = Self-Transcendence Character Scale; ST1 = ST Selfforgetfulness subscale; ST2 = ST Transpersonal identification subscale; ST3 = ST Spiritual acceptance subscale .

${ }^{\dagger} n=58, * p<.05, * * p<.01, * * * p<.001$ 